\title{
Modeling the Joint Choice Decisions on Urban Shopping Destination and Travel-to-Shop Mode: A Comparative Study of Different Structures
}

\author{
Chuan Ding, Binglei Xie, Yaowu Wang, and Yaoyu Lin \\ Shenzhen Key Laboratory of Urban Planning and Decision Making Simulation, Shenzhen Graduate School, Harbin Institute of \\ Technology, Shenzhen 518055, China \\ Correspondence should be addressed to Binglei Xie; xiebingleihit@163.com
}

Received 5 November 2013; Revised 10 February 2014; Accepted 12 February 2014; Published 13 March 2014

Academic Editor: Huimin Niu

Copyright (c) 2014 Chuan Ding et al. This is an open access article distributed under the Creative Commons Attribution License, which permits unrestricted use, distribution, and reproduction in any medium, provided the original work is properly cited.

\begin{abstract}
The joint choice of shopping destination and travel-to-shop mode in downtown area is described by making use of the cross-nested logit (CNL) model structure that allows for potential interalternative correlation along the both choice dimensions. Meanwhile, the traditional multinomial logit (MNL) model and nested logit (NL) model are also formulated, respectively. This study uses the data collected in the downtown areas of Maryland-Washington, D.C. region, for shopping trips, considering household, individual, land use, and travel related characteristics. The results of the model reveal the significant influencing factors on joint choice travel behavior between shopping destination and travel mode. A comparison of the different models shows that the proposed CNL model structure offers significant improvements in capturing unobserved correlations between alternatives over MNL model and NL model. Moreover, a Monte Carlo simulation for a group of scenarios assuming that there is an increase in parking fees in downtown area is undertaken to examine the impact of a change in car travel cost on the joint choice of shopping destination and travel mode switching. The results are expected to give a better understanding on the shopping travel behavior.
\end{abstract}

\section{Introduction}

Both of the destination choice and travel mode choice for shopping trips play important roles in travel demand analysis and transportation policy assessment. Consequently, understanding factors influencing travelers' destination and travel mode choice is necessary to examine the potential effectiveness of policy measures. Previous studies have widely focused on the destination choice [1-3] and travel mode choice $[4,5]$, respectively. In the past few years, research on joint choice travel behavior was focused primarily on the field of travel mode and departure time [6,7], as well as residential location and travel mode $[8,9]$. As many researchers mentioned, there is a strong relationship between shopping destination and travel mode choice, and people also often make the two decisions simultaneously [10]. Joint analysis of shopping destination and travel mode is helpful to understand the interactions between them and is necessary to assess the impact of the transport policies.
Multinomial logit (MNL) model and nested logit (NL) model based on random utility maximization have been most widely used to analyze travel behavior [11]. However, the MNL model imposes the restriction that the distribution of random error terms is independent and identical over alternatives, which leads to the independence of irrelevant alternatives (IIA) property. Therefore, unobserved similarities existing among choice alternatives in MNL model are overlooked. The most widely known relaxation of MNL model is the NL model. For the NL model, a uniform amount of correlation within a nest of alternatives is allowed, but alternatives not located in the same nest are uncorrelated [12]. For the joint choice analysis of shopping destination and travel mode, two appropriate structures based on the NL model can be described: one is used to nest by shopping destination; another is used to nest by travel mode. However, the both structures can only accommodate correlation along one of the two dimensions. In recent years, the CNL model 
has received more attentions in the literature, which allows alternatives to belong to more than one nest instead of each alternative being restricted to a single nest in NL model [13, 14]. Therefore, the CNL model has a more flexible correlation structure to account for various patterns of similarity and dissimilarity among alternatives $[8,15]$.

In summary, shopping destination choice has received relatively less attention than other travel behaviors such as travel mode and departure time $[16,17]$. Studies on simultaneous choice analysis of shopping destination and travel mode that allows for the flexible correlations along the both choice dimensions are limited. In addition, most previous studies just only focused on analyzing the influencing factors for the travel behavior of shopping destination and travel mode choice, while simulation approach related to transport policies based on the estimated model is limited.

In this study, the simultaneous choice of shopping destination and travel mode is described by using a new CNL structure that allows for the joint representation of interalternative correlation along the both choice dimensions. Traditional MNL model and NL model are also formulated, respectively, and a comprehensive study to compare the different model structures is carried out. Moreover, based on the estimated model, a Monte Carlo simulation for a series of scenarios assuming that there is an increase in parking fees in downtown area is undertaken to examine the effects of a change in car travel cost on the joint choice of shopping destination and travel mode switching.

The remainder of this paper is organized as follows. The next section presents the model structures used in this study. The third section describes the data used for the model and the fourth section presents the model results. In the fifth section a change in car travel cost due to higher parking fees is simulated based on Monte Carlo method. The final section provides a summary and conclusions.

\section{Model Specification}

In contrast to previous studies on shopping destination choice, the shopping destination choice set in this paper is a selection of spatial areas according to the shopping distance from home location rather than a selection of zones. Therefore, in this study, home location is assumed to be exogenous. Shopping destination and travel behavior are concentrated within the downtown area, which is a classic example of the monocentric city. So the trips are generated by residents who dwell in the central business district (CBD). Therefore, the shopping destination choice set is based on a series of concentric road-distance rings around the residence. The shopping distance is measured between residential and shopping destination. Travel time and travel cost are computed as a function of shopping distance, which can be obtained from the Maryland Statewide Transportation Model (MSTM).

The shopping destination subset has 3 alternatives consisting of concentric road-distance rings around residence within 1 mile, 1-2 miles, and over 2 miles. The travel mode
TABLE 1: Alternatives for joint choice of shopping destination and travel-to-shop mode.

\begin{tabular}{lcc}
\hline Alternatives & $\begin{array}{c}\text { Distance to shop from } \\
\text { home location }\end{array}$ & Mode of travel to shop \\
\hline Alternative 1 & Within 1 mile & Car \\
Alternative 2 & Within 1 mile & Transit \\
Alternative 3 & Within 1 mile & Walk and bicycle \\
Alternative 4 & 1-2 miles & Car \\
Alternative 5 & $1-2$ miles & Transit \\
Alternative 6 & $1-2$ miles & Walk and bicycle \\
Alternative 7 & Over 2 miles & Car \\
Alternative 8 & Over 2 miles & Transit \\
Alternative 9 & Over 2 miles & Walk and bicycle \\
\hline
\end{tabular}

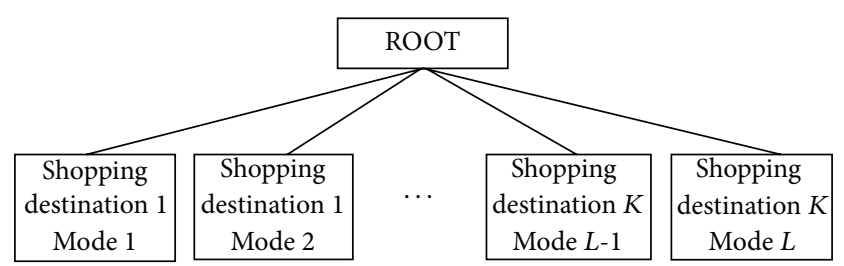

FIgURE 1: Structure of MNL model.

choice subset consists of 3 modes of home-based travel-toshop: car, transit, walk, and bicycle. Therefore, the model choice set is defined as the joint choice set of shopping destination and travel mode, which creates a set of $N=$ 9 alternatives for each decision-maker located at CBD, as shown in Table 1.

2.1. Multinomial Logit and Nested Logit Models. In the past few years, many discrete choice models were developed based on the generalized extreme value (GEV) theory proposed by McFadden [18]. The GEV models are able to capture the unobserved similarities among alternatives, thus relaxing the restriction of MNL and NL models. Several specific GEV models have been formulated by Wen and Koppelman [19] and by Daly and Bierlaire [20]. In this study, all the model structures are presented based on the GEV model framework to analyze the joint choice behavior of shopping destination and travel mode, in order to capture the unobserved correlations between alternatives.

The basic structure tested is an MNL model assuming that no correlations exist between any of the alternatives. The nesting structure is shown in Figure 1.

There are two possible two-level NL structures based on nesting different dimensions of the choice. For example, one appropriate NL structure for the two-level combined model based on nesting by shopping destination is shown in Figure 2, with shopping destination at the upper level and travel mode at the lower level. Alternatives are grouped together based on the shopping destination dimension. In the two-level NL structure, each nest has its own nesting parameter $\mu(0<\mu \leq 1)$. The nesting parameter can be used to capture the correlations between alternatives sharing 


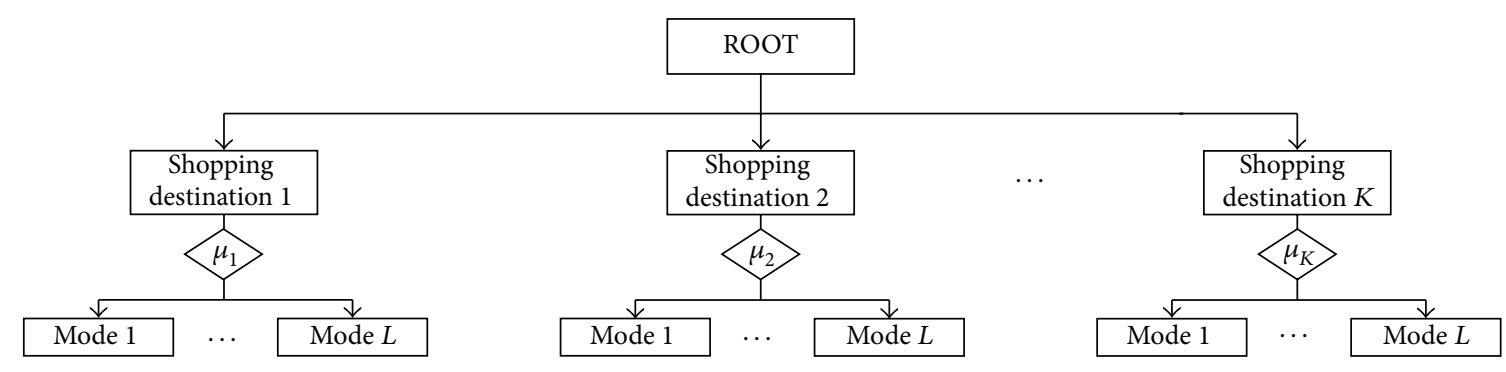

FIgURE 2: Structure of two-level NL model, using nesting along shopping destination dimension.

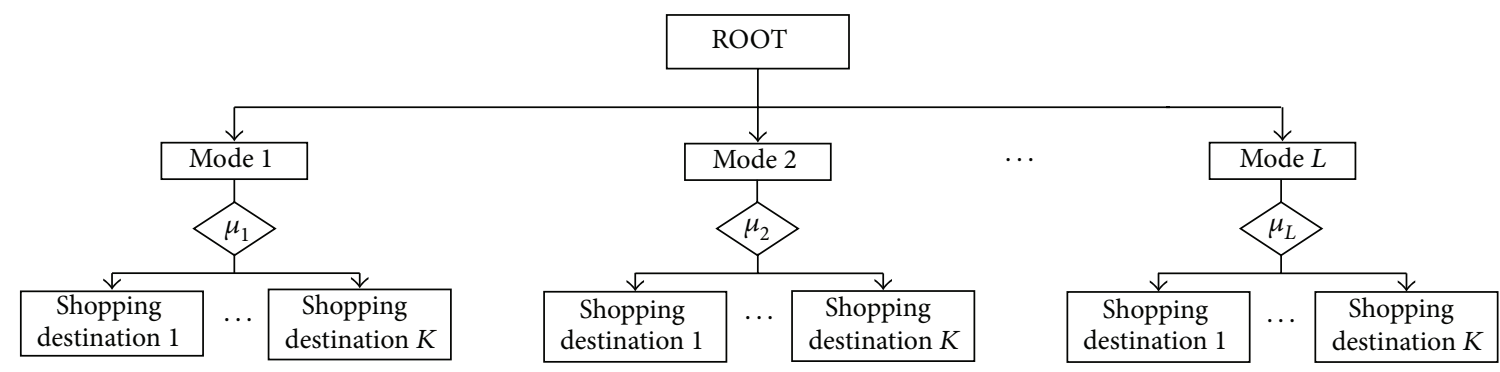

FIGURE 3: Structure of two-level NL model, using nesting along travel mode dimension.

the nest of shopping destination. It is also called dissimilarity parameter. The correlation between alternatives sharing the same nest increases as the dissimilarity parameter decreases.

Figure 3 shows another nesting structure that alternatives are grouped together based on the travel mode dimension. The NL structure shown in Figures 2 and 3 can only be used to analyze the correlation along only one of the two dimensions. They cannot be used to analyze the correlations along the two dimensions of choice simultaneously. For example, the model structure shown in Figure 2 cannot be used to capture spatial correlation between alternative using mode $L$ to destination $K_{1}$ and the alternative using mode $L$ to destination $K_{2}$. In general, if there are $K$ dimensions in the choice process, joint choice NL model used in most previous studies can only be used to analyze the correlations along at most $K-1$ of $K$ dimensions by using a multilevel structure.

2.2. Cross-Nested Logit Model. The deficiencies of the MNL and NL model structures were first discussed by Hess and Polak in the context for air travel behavior [15]. The solution put forward by Hess and Polak is to use a CNL model structure. It is one motivation for the efforts made in this study to propose improved structures for the joint choice of shopping destination and travel mode. Based on the previous studies, a new CNL model structure is proposed in Figure 4. As shown in Figure 4, the structure for the joint choice model is specified by allowing each alternative to belong to exactly one nest in each shopping destination and travel mode groups. As such, the structure of the model is able to accommodate full correlations along all the dimensions using the simultaneous pattern. In this paper, the allocation parameters $\alpha(0 \leq \alpha \leq 1)$, governing the proportion by which an alternative belongs to each nest, can also be obtained based on the GEV structure. A value of zero indicates that the alternative does not belong to the nest at all. It is usually specified that the allocation parameters for a given alternative must sum to unity over all nests. In this study, the nonzero allocation parameters for a given alternative were fixed to a value of 0.5 , indicating that an alternative belongs by the same proportion to one shopping destination nest and one travel mode nest. As such, the improved structure of the model is able to accommodate the correlations between alternatives along all the dimensions using the simultaneous pattern.

2.3. Model Formulation. As a specific GEV model, the CNL model is formulated for the joint probability choice of shopping destination and home-based travel-to-shop mode. There are two main advantages for the application of the CNL structure. On one hand, the CNL model structure provides a more flexible correlation structure of the error term that allows the potential correlations between alternatives to be captured along the both choice dimensions. On the other hand, the CNL mode structure has closed-form expression derived for the calculation of the choice probability.

According to the GEV theorem $[18,19,21]$, the CNL model choice probability derived from the generator function presented in (1) is defined in terms of conditional and marginal probabilities as shown in (2):

$$
\begin{gathered}
G(y)=\sum_{m}\left(\sum_{k}\left(\alpha_{m} y_{k}\right)^{1 / \mu_{m}}\right)^{\mu_{m}}, \\
P(k)=\sum_{m} P(k \mid m) P(m),
\end{gathered}
$$

where $k$ represents an alternative; $m$ represents a nest; $\mu_{m}$ is a nest-specific coefficient; $\alpha_{m}$ is a weight parameter; 


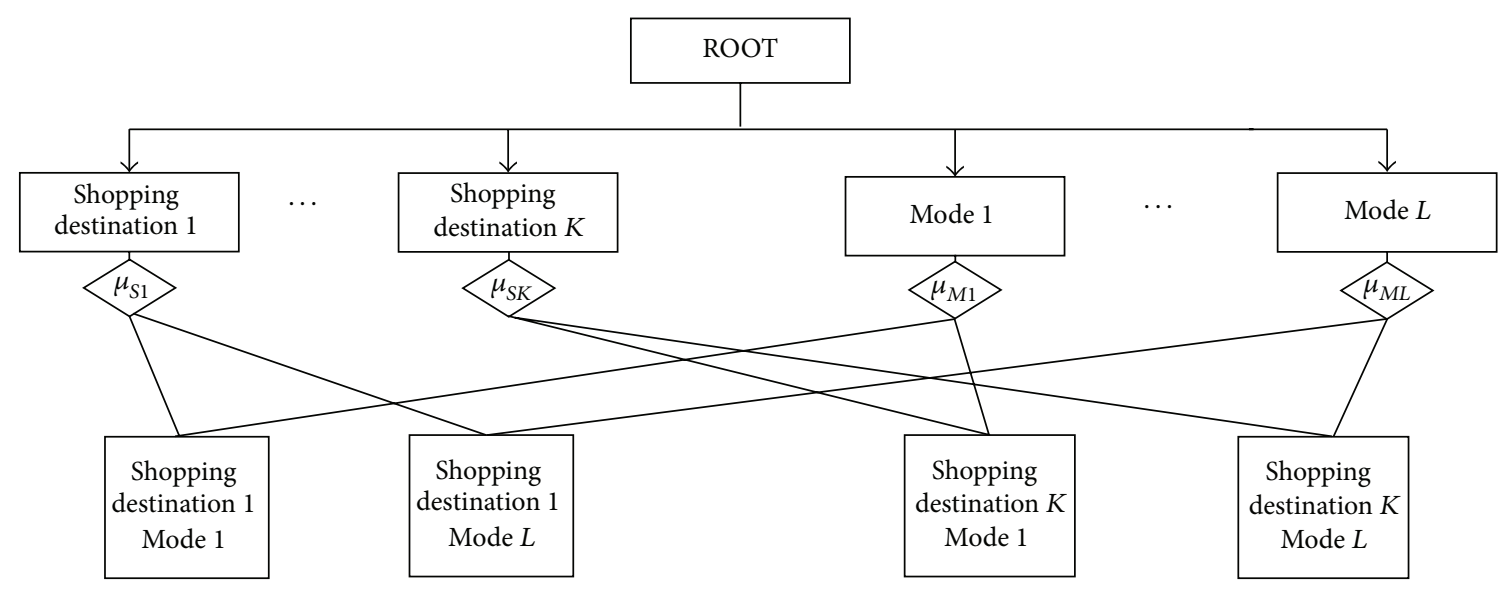

FIGURE 4: Structure of two-level CNL model, using nesting along the shopping destination and travel mode.

the conditional probability of an alternative $k$ being chosen in nest $m$ is as follows:

$$
P(k \mid m)=\frac{\left(\alpha_{m k} e^{V_{k}}\right)^{1 / \mu_{m}}}{\sum_{k}\left(\alpha_{m k} e^{V_{k}}\right)^{1 / \mu_{m}}},
$$

where $\alpha_{m k}$ is an allocation parameter that characterized the portion of alternative $k$ assigned to nest $m, 0 \leq \alpha_{m k} \leq 1$. And the marginal probability of a nest $m$ being chosen is shown as follows:

$$
P(m)=\frac{\left(\sum_{k}\left(\alpha_{m k} e^{V_{k}}\right)^{1 / \mu_{m}}\right)^{\mu_{m}}}{\sum_{m}\left(\sum_{k}\left(\alpha_{m k} e^{V_{k}}\right)^{1 / \mu_{m}}\right)^{\mu_{m}}} .
$$

Thus, the probability of the CNL alternative $k$ being chosen is shown as follows:

$$
\begin{aligned}
P(k) & =\sum_{m} P(k \mid m) P(m) \\
& =\sum_{m}\left(\frac{\left(\alpha_{m k} e^{V_{k}}\right)^{1 / \mu_{m}}}{\sum_{k}\left(\alpha_{m k} e^{V_{k}}\right)^{1 / \mu_{m}}} \cdot \frac{\left(\sum_{k}\left(\alpha_{m k} e^{V_{k}}\right)^{1 / \mu_{m}}\right)^{\mu_{m}}}{\sum_{m}\left(\sum_{k}\left(\alpha_{m k} e^{V_{k}}\right)^{1 / \mu_{m}}\right)^{\mu_{m}}}\right) .
\end{aligned}
$$

In (5), there are two key factors on which the probability of the alternative $k$ choosing depends: nesting coefficients $\mu_{m}$ and deterministic component $V_{k}$ of the utility function. In this study, the parameters are estimated based on maximum likelihood method.

\section{Data Sources and Sample Formation}

The data used in this study is drawn from the Baltimore and Washington regional household travel survey (HTS), which was conducted by Baltimore Metropolitan Council (BMC) and Transportation Planning Board at the Metropolitan Washington Council of Governments (MWCOG) during 2007-2008. The areas selected for this analysis is the Baltimore
City and Washington, D.C., which are the downtown areas of the Maryland-Washington, D.C. region. In addition to the HTS dataset, there are other three important sources of data used in the analysis: origin-destination travel time and cost matrices by different modes from Maryland Statewide Transportation Model (MSTM); digital data for GIS analysis provided by National Center for Smart Growth (NCSG) at the University of Maryland; and land use and employment data in traffic analysis zones (TAZs) from Metropolitan Planning Organizations (MPOs) and Quarterly Census Employment and Wages (QCEW).

Many factors have been identified that influence the decisions of shopping destination and travel mode [8, 22, 23]. There are four variable groups used in this analysis: household, individual, land use related, and travel related characteristics. The variables of household characteristics include household size, income, and the number of cars available in the household. The variables of individual characteristics include gender and age. The built environment at the home-located TAZ is found to be potentially important variables influencing the choice of shopping destination in many previous studies. In this study, population density and retail employment density at the TAZ level are used as land use related explanatory variables. Travel related characteristics include travel time and travel cost computed from home location to shopping destination by different travel modes. The total variables used in analysis are shown in Table 2.

The distributions of shopping distance and travel time for all trips are shown in Figures 5 and 6. The distribution of shopping distance shows that the shopping trips decrease as the distance from home increases, which is consistent with expectations. Most shoppers tend to make shopping trips within one mile distance from home. Figure 6 shows that most shoppers tend to take less than twenty minutes for their shopping trips.

A descriptive analysis is conducted to get intuitive findings regarding the association between household, individual, land use related characteristics and the preferences of shopping destination and travel mode. As shown in Table 3, 
TABLE 2: Descriptive statistics of the sample data for home-based travel-to-shop trips $(N=975)$.

\begin{tabular}{|c|c|c|c|}
\hline Variable name & Variable description & Mean & St. Dev. \\
\hline \multicolumn{4}{|c|}{ Household characteristics } \\
\hline \multirow{3}{*}{ Household size } & Single person household $(1=$ yes; $0=$ otherwise $)$ & 0.34 & 0.475 \\
\hline & Household size is equal to two persons $(1=$ yes; $0=$ otherwise $)$ & 0.44 & 0.496 \\
\hline & Household size is equal to or more than three persons ( $1=$ yes; $0=$ otherwise $)$ & 0.22 & 0.414 \\
\hline \multirow{3}{*}{ Household income } & Household income is less than $\$ 30,000$ ( $1=$ yes; $0=$ otherwise) & 0.23 & 0.422 \\
\hline & Household income is between $\$ 30,000$ and $\$ 100,000$ ( $1=$ yes; $0=$ otherwise) & 0.42 & 0.494 \\
\hline & Household income is equal to or more than $\$ 100,000(1=$ yes; $0=$ otherwise $)$ & 0.35 & 0.477 \\
\hline \multirow{3}{*}{ Cars ownership } & Household owns no car $(1=$ yes; $0=$ otherwise $)$ & 0.22 & 0.415 \\
\hline & Household owns one car $(1=$ yes; $0=$ otherwise $)$ & 0.42 & 0.494 \\
\hline & Household owns two or more cars $(1=$ yes; $0=$ otherwise $)$ & 0.36 & 0.479 \\
\hline \multicolumn{4}{|c|}{ Individual characteristics } \\
\hline Gender & Male $(1=$ yes; $0=$ otherwise $)$ & 0.45 & 0.498 \\
\hline \multirow{3}{*}{ Age } & Person is less than 25 years old $(1=$ yes; $0=$ otherwise $)$ & 0.05 & 0.210 \\
\hline & Person is between 25 and 54 years old ( $1=$ yes; $0=$ otherwise $)$ & 0.52 & 0.500 \\
\hline & Person is equal to or more than 55 years old ( $1=$ yes; $0=$ otherwise $)$ & 0.44 & 0.496 \\
\hline \multicolumn{4}{|c|}{ Land use related characteristics } \\
\hline Residential density & Continuous variable: residential density of TAZ in which home lies (people/acre) & 25.37 & 18.049 \\
\hline Retail employment density & $\begin{array}{l}\text { Continuous variable: retail employment density of TAZ in which home lies (retail } \\
\text { employment/acre) }\end{array}$ & 2.98 & 5.878 \\
\hline \multicolumn{4}{|c|}{ Travel related characteristics } \\
\hline Travel Time & \multicolumn{3}{|c|}{ Continuous variable: total time of a trip $(\mathrm{min})$ provided by MSTM } \\
\hline Travel cost & \multicolumn{3}{|c|}{ Continuous variable: total travel cost for a trip (\$) as a function of distance provided by MSTM } \\
\hline \multicolumn{4}{|c|}{ Choice characteristics } \\
\hline Shopping destination & \multicolumn{3}{|l|}{ Distance to shop: within 1 mile, $1-2$ miles, and over 2 miles } \\
\hline Travel mode & \multicolumn{3}{|l|}{ Trip modes: car, transit, walk, and bicycle } \\
\hline
\end{tabular}

TABLE 3: Sample profiles stratified by shopping destination and travel mode $(N=975)$.

\begin{tabular}{|c|c|c|c|c|c|c|}
\hline \multirow{2}{*}{ Frequencies (\%) } & \multicolumn{3}{|c|}{ Shopping destination } & \multicolumn{3}{|c|}{ Travel mode } \\
\hline & Within 1 mile & 1-2 miles & Over 2 miles & Car & Transit & Walk and bicycle \\
\hline \multicolumn{7}{|l|}{ Household size } \\
\hline Single person & 44.6 & 14.6 & 40.8 & 48.2 & 27.6 & 34.2 \\
\hline Two persons & 36.2 & 17.9 & 45.9 & 59.1 & 12.2 & 28.7 \\
\hline More than two persons & 42.1 & 19.2 & 38.8 & 69.6 & 6.1 & 24.3 \\
\hline \multicolumn{7}{|l|}{ Household income } \\
\hline$<\$ 30,000$ & 46.9 & 14.2 & 38.9 & 41.6 & 25.7 & 32.7 \\
\hline$\$ 30,000-\$ 100,000$ & 38.1 & 17.6 & 44.3 & 62.8 & 9.8 & 27.4 \\
\hline$>\$ 100,000$ & 38.8 & 18.2 & 42.9 & 62.1 & 7.6 & 30.3 \\
\hline \multicolumn{7}{|l|}{ Cars ownership } \\
\hline No car & 56.3 & 12.1 & 31.6 & 7.4 & 38.1 & 54.4 \\
\hline One car & 40.2 & 18.6 & 41.2 & 64.2 & 6.8 & 29.1 \\
\hline More than one car & 30.8 & 18.2 & 51.0 & 81.0 & 4.0 & 15.0 \\
\hline \multicolumn{7}{|l|}{ Gender } \\
\hline Male & 42.4 & 18.1 & 39.5 & 55.6 & 12.7 & 31.7 \\
\hline Female & 38.8 & 16.1 & 45.1 & 59.4 & 12.7 & 27.9 \\
\hline \multicolumn{7}{|l|}{ Age } \\
\hline $16-24$ & 33.3 & 11.1 & 55.6 & 57.8 & 8.9 & 33.3 \\
\hline $25-54$ & 42.7 & 16.1 & 41.2 & 52.5 & 12.9 & 34.6 \\
\hline$>55$ & 38.4 & 18.7 & 42.9 & 63.7 & 12.9 & 23.4 \\
\hline
\end{tabular}




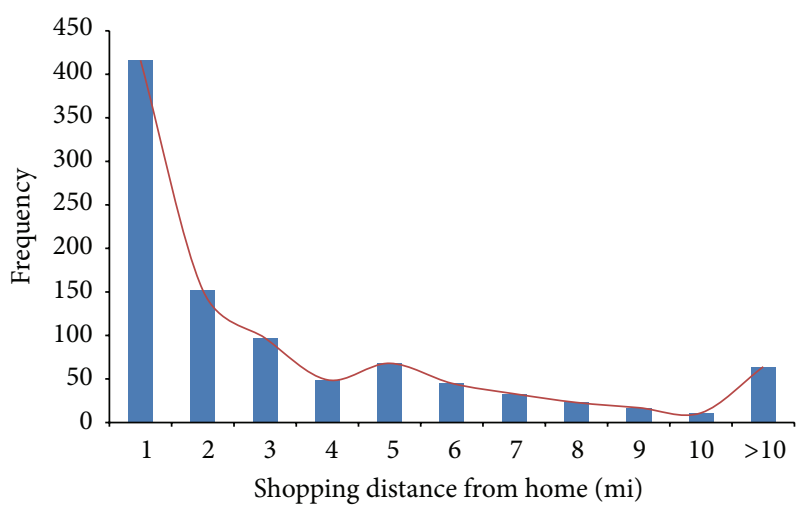

FIgURE 5: Distribution of shopping distance for the home-based travel-to-shop trips.

young individuals are more likely to shop farther away from home and they are also found to show a negative propensity to use transit. This may be seen as an intuitive characterrelated effect for young individuals. As expected, people from smaller household size, lower household income, and lower car ownership are found to be more likely to shop closer from home and use transit or walk and bicycle for shopping trips.

\section{Empirical Results}

All the models presented in this study were estimated using Biogeme $[24,25]$, including the MNL model, two kinds of NL model, and the proposed CNL model. The probability of choosing each alternative can be estimated using the presented model based on the given independent variables.

The travel-related parameters, data fit measures, and dissimilarity parameters for the four models are presented in Table 4. In terms of adjusted $\rho^{2}$, it can be seen that the MNL model and the first NL model outperform others. In terms of the log-likelihood, the final log-likelihood value of the CNL is -1307.762 , which is $0.846,0.509$, and 56.683 points higher, respectively, than that of the MNL model and the other two kinds of NL model. As expected, the signs of the travelrelated parameters are negative. The average value of travel time savings for the shopping trips is about $0.19 \$ / \mathrm{min}$ (about $11.5 \$$ /hour), which is lower than the value for commuting trips reported by Hess et al. [26].

In terms of the unobservable correlations between alternatives, as seen from Table 4 , the CNL model is superior in capturing the unobservable correlation between alternatives when compared to the MNL and the other two kinds of NL model. The dissimilarity parameter along the transit dimension is minimal, indicating that the alternatives in the transit nest have high correlations. In other words, the dissimilarity parameters capture the pattern of substitutability across alternatives $[19,27]$. Due to the high substitutability of the alternatives in the transit nest, the decision-makers are more likely to shift their shopping destination rather than their travel mode when the values of the utility variables change (such as due to transportation control measures).

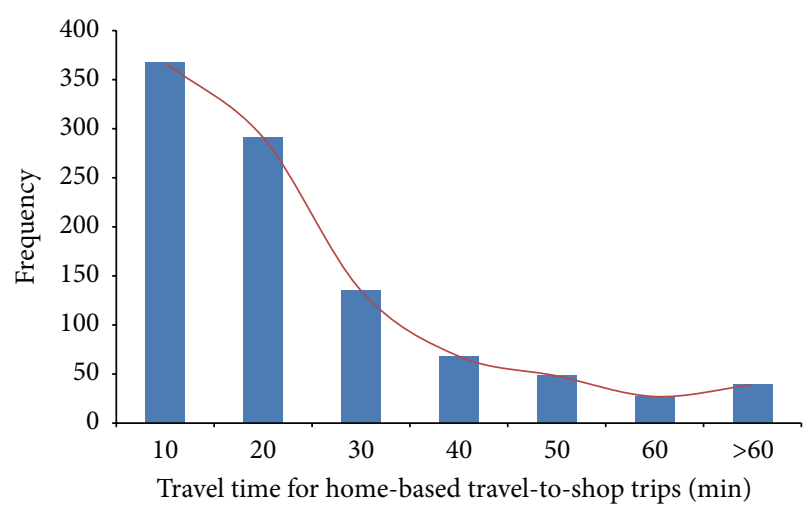

FIGURE 6: Distribution of travel time for the home-based travel-toshop trips.

The mean value of the dissimilarity parameter for the shopping travel mode is lower than that for shopping destination, which means that the shoppers who live in the downtown area are more likely to shift their travel mode than shopping destination.

The detailed estimation results based on the CNL model are presented in Table 5. The model results suggest that these household, individual, and land use characteristics in the case study area are the important factors influencing the individuals' shopping destination and travel mode choice decisions. In terms of the household characteristics, it can be seen from Table 5 that single person is significantly less likely to shop by transit when the shopping destination is 1-2 miles away home, compared with the base alternative. People from the larger households are significantly more likely to shop closer from home and significantly less likely to walk to shop. Low income groups are found to choose shopping destinations closer from home using transit, compared with the base alternative. However, they are found significantly less likely to walk to shop. Higher income groups show a positive propensity to walk to shop, compared with the base alternative, though it is less significant at the 95 percent level. As expected, low car ownership level is found to show a significantly negative propensity to drive to shop. People with more cars available are significantly less likely to walk to shop even if the shopping destination is within 1 mile from home. In terms of the individual characteristics, the variable of gender is found to be less significant. Young adults are significant more likely to walk to the shopping destination further away from home. Older individuals are found to be more likely to drive to shop than younger individuals when the shopping destination is within 1 mile from home. In terms of the land use related characteristics, it is found that people who live in high residential density and retail employment density areas are significantly more likely to walk to shop within 1 mile from home.

\section{Monte Carlo Simulation}

The traffic problem becomes much serious in the downtown areas. Therefore, the simulation tests on different scenarios 
TABLE 4: Travel related parameter and data fit measures $(N=975)$.

\begin{tabular}{|c|c|c|c|c|c|c|c|c|}
\hline \multirow{2}{*}{$\begin{array}{l}\text { Attributes, dissimilarity } \\
\text { parameter, and data fit } \\
\text { measures }\end{array}$} & \multicolumn{2}{|c|}{ MNL } & \multicolumn{2}{|c|}{$\begin{array}{l}\text { NL using nesting by } \\
\text { shopping destination }\end{array}$} & \multicolumn{2}{|c|}{$\begin{array}{l}\text { NL using nesting by } \\
\text { travel mode }\end{array}$} & \multicolumn{2}{|c|}{$\begin{array}{l}\text { CNL using nesting by } \\
\text { shopping destination } \\
\text { and travel mode }\end{array}$} \\
\hline & Parameter & $t$-stat & Parameter & $t$-stat & Parameter & $t$-stat & Parameter & $t$-stat \\
\hline Travel cost & -0.392 & -6.42 & -0.392 & -6.39 & -0.346 & -6.60 & -0.389 & -6.36 \\
\hline Travel time & -0.0754 & -9.52 & -0.0755 & -9.51 & -0.0643 & -9.81 & -0.0754 & -9.66 \\
\hline$\mu_{\text {destination } 1}$ & 1.00 & - & 1.00 & - & - & - & 1.06 & 0.10 \\
\hline$\mu_{\text {destination2 }}$ & 1.00 & - & 1.00 & 6.49 & - & - & 1.62 & 0.30 \\
\hline$\mu_{\text {destination3 }}$ & 1.00 & - & 1.00 & 4.96 & - & - & 1.48 & 1.16 \\
\hline$\mu_{\mathrm{car}}$ & 1.00 & - & - & - & 1.00 & - & 1.00 & 0.03 \\
\hline$\mu_{\text {transit }}$ & 1.00 & - & - & - & 2.04 & 7.57 & 1.02 & 0.16 \\
\hline$\mu_{\text {walk }}$ & 1.00 & - & - & - & 1.26 & 3.65 & 1.00 & 0.04 \\
\hline VTTS (\$/min) & \multicolumn{2}{|c|}{0.1923} & \multicolumn{2}{|c|}{0.1926} & \multicolumn{2}{|c|}{0.1858} & \multicolumn{2}{|c|}{0.1938} \\
\hline Final LL & \multicolumn{2}{|c|}{-1308.608} & \multicolumn{2}{|c|}{-1308.271} & \multicolumn{2}{|c|}{-1364.445} & \multicolumn{2}{|c|}{-1307.762} \\
\hline Adjusted $\rho^{2}$ & \multicolumn{2}{|c|}{0.343} & \multicolumn{2}{|c|}{0.343} & \multicolumn{2}{|c|}{0.316} & \multicolumn{2}{|c|}{0.333} \\
\hline Parameters & \multicolumn{2}{|c|}{98} & \multicolumn{2}{|c|}{100} & \multicolumn{2}{|c|}{100} & \multicolumn{2}{|c|}{122} \\
\hline
\end{tabular}

Note. Alternative 1 is the reference category; LL: log-likelihood; VTTS: value of travel time savings.

are extremely useful for the transportation demand management (TDM), transportation control measures (TCM), and intelligent transportation system (ITS). In this study, another important motivation lies in obtaining the simulated results when the travel-related attributes change arising from transport policies, using the empirical results to test the impact of a change in travel cost on the joint choice of the shopping destination and travel mode switching.

Most transportation congestion management actions attempt to affect the mode choice behavior or reduce trip making by directly or indirectly impacting the level-ofservice variables. For example, congestion pricing and parking fees rely on the use of monetary disincentives for the car mode. In this study, a group of simulations is carried out by assuming that there is an increase in car travel cost due to the higher parking fees in the downtown area.

Sample enumeration is used to calculate the joint choice probabilities for each shopper based on the estimated parameters presented in Table 5. This is extremely useful for producing the aggregate shares for all alternatives. To produce the analysis of the impact of a change in travel-related attributes, the simulated choices following the change can be obtained based on the Monte Carlo simulation using the estimated model. Then the correct predicted probabilities for all alternatives can be calculated based on the simulated each choice. It is found that the predicted shares are very close to the actual shares, as shown in Table 6. Therefore, the CNL model can be used to accurately represent the choice shares in the study area.

The simulated results for one dollar, two and one half dollars, and five dollars increasing in car travel cost due to higher parking fees are presented in Table 7. As expected, the simulated results show that the choice probability of driving decreases with the car travel cost increasing. Specially, the effect of higher parking fees is more significant for the long shopping distance. The shares of using car to far away from home (i.e., over 2 miles) for shopping sharply decrease when there is a higher parking fees. Most shoppers living in the downtown area will shift from car mode to walk or bicycling for shopping trips to reduce their transport spending. In this case, it is important to provide a suitable walking environment and provide a better neighborhood design for the pedestrian. Otherwise, the people will still choose the car mode to shop because of the bad pedestrian environment, and the policy of a change in parking fees will fail.

\section{Conclusion}

In this study, the joint choice of shopping destination and travel-to-shop mode is analyzed, using three different types of GEV structures: MNL model, two types of the NL, and a new CNL model. A combination of data sources is used to estimate the choice of models for the downtown areas in Maryland-Washington, D.C. region. As the estimated results showed, unobserved similarities which exist among choice alternatives are overlooked in the MNL model, the use of twolevel NL models can allow for the treatment of correlation along a single dimension of choice, and the proposed CNL model can capture the unobserved correlations along the both shopping destination and travel mode dimensions. In terms of model performance, the CNL model outperforms other models in general. Therefore, the CNL model can be seen as a valuable tool in the analysis of the joint choice of shopping destination and travel model. The model results show that household, individual, land use, and travel related characteristics play different roles in the joint choice behavior of shopping destination and travel mode.

A series of simulations are conducted for increasing car travel cost to forecast the aggregate choice shares, using the sample enumeration method. Significant choice switching effects are found, and the simulated results suggest that 


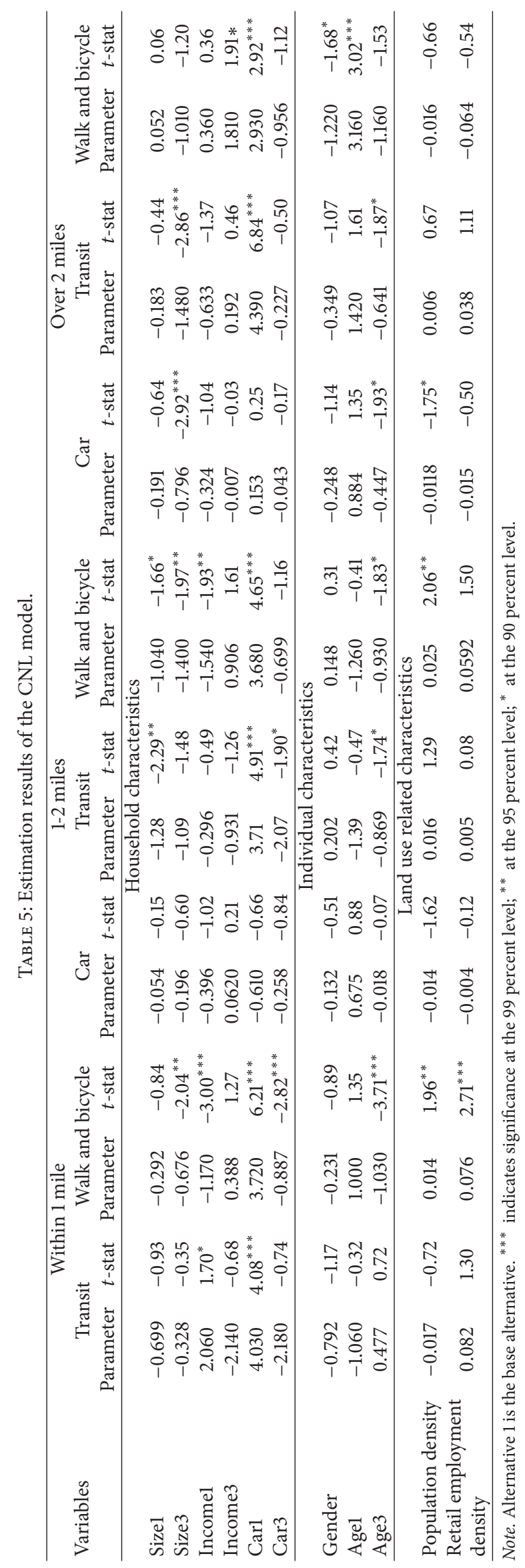


TABLE 6: Comparisons between actual shares and predicted shares using sample enumeration.

\begin{tabular}{lccccccccc}
\hline \multirow{2}{*}{ Actual/predicted shares (\%) } & \multicolumn{2}{c}{ Within 1 mile } & \multicolumn{2}{c}{$1-2$ miles } & \multicolumn{2}{c}{ Over 2 miles } \\
& Car & Transit & Walk and bicycle & Car & Transit & Walk and bicycle & Car & Transit & Walk and bicycle \\
\hline Actual shares & 12.9 & 1.5 & 25.9 & 12.0 & 2.6 & 2.5 & 32.7 & 8.6 & 1.2 \\
Predicted shares & 12.4 & 1.7 & 25.6 & 12.2 & 2.6 & 2.3 & 33.4 & 8.5 & 1.4 \\
\hline
\end{tabular}

TABLE 7: Predicted shares based on different scenarios.

\begin{tabular}{lccccccccc}
\hline \multirow{2}{*}{ Scenario group (\%) } & \multicolumn{3}{c}{ Within 1 mile } & \multicolumn{2}{c}{ 1-2 miles } & \multicolumn{2}{c}{ Over 2 miles } \\
& Car & Transit & Walk and bicycle & Car & Transit & Walk and bicycle & Car & Transit & Walk and bicycle \\
\hline Base scenario & 12.4 & 1.7 & 25.6 & 12.2 & 2.6 & 2.3 & 33.4 & 8.5 & 1.4 \\
One dollar & 11.5 & 1.6 & 28.8 & 11.0 & 2.9 & 2.5 & 30.6 & 9.3 & 1.6 \\
Two and one half dollars & 9.7 & 2.1 & 33.4 & 9.4 & 3.3 & 2.9 & 25.8 & 11.4 & 1.9 \\
Five dollars & 6.8 & 2.2 & 41.5 & 6.4 & 4.0 & 3.6 & 17.8 & 15.3 & 2.4 \\
\hline
\end{tabular}

transport policies aimed at reducing traffic congestion in downtown areas by increasing car travel cost may have better effects; however improving the pedestrian environment is also necessary.

Charging for the road user has been seen by some academics and urban planners as a solution to traffic problems in the city. The framework presented in this paper has more potential application in the future, such as the impact study of a hypothetical road user charging scheme and the effect analysis of parking charges, transit subsidies, and flexible work hours on a traveler's behavior. Further studies will not only include the application of the framework based on the CNL model but also include the use of advanced model structures allowing joint for the cross-nesting, continuous deterministic, and random taste heterogeneity to exam the shopper travel behavior.

\section{Conflict of Interests}

The authors declare that there is no conflict of interests regarding the publication of this paper.

\section{Acknowledgments}

This research is supported in part by the National Natural Science Foundation of China (no. 71173061), Shenzhen Science and Technology Development Funding-Fundamental Research Plan (Grant JCYJ20120615145601342), and Key Laboratory of Eco Planning \& Green Building, Ministry of Education (Tsinghua University, 2013U-6).

\section{References}

[1] W. W. Recker and L. P. Kostyniuk, "Factors influencing destination choice for the urban grocery shopping trip," Transportation, vol. 7, no. 1, pp. 19-33, 1978.

[2] C. R. Bhat and J. Guo, "A mixed spatially correlated logit model: formulation and application to residential choice modeling," Transportation Research Part B, vol. 38, no. 2, pp. 147-168, 2004.

[3] A. Sivakumar and C. R. Bhat, "Comprehensive, unified framework for analyzing spatial location choice," Transportation Research Record, no. 2003, pp. 103-111, 2007.
[4] C. R. Bhat, "Work travel mode choice and number of non-work commute stops," Transportation Research Part B, vol. 31, no. 1, pp. 41-54, 1997.

[5] A. de Palma and D. Rochat, "Mode choices for trips to work in Geneva: an empirical analysis," Journal of Transport Geography, vol. 8, no. 1, pp. 43-51, 2000.

[6] C. A. Tringides, X. Ye, and R. M. Pendyala, "Departuretime choice and mode choice for nonwork trips alternative formulations of joint model systems," Transportation Research Record, no. 1898, pp. 1-9, 2004.

[7] S. Bajwa, S. Bekhor, M. Kuwahara, and E. Chung, "Discrete choice modeling of combined mode and departure time," Transportmetrica, vol. 4, no. 2, pp. 155-177, 2008.

[8] A. Vega and A. Reynolds-Feighan, "A methodological framework for the study of residential location and travel-to-work mode choice under central and suburban employment destination patterns," Transportation Research Part A, vol. 43, no. 4, pp. 401-419, 2009.

[9] L. Yang, G. Zheng, and X. Zhu, "Cross-nested logit model for the joint choice of residential location, travel mode, and departure time," Habitat International, vol. 38, pp. 157-166, 2013.

[10] J. Scheiner, "Interrelations between travel mode choice and trip distance: trends in Germany 1976-2002," Journal of Transport Geography, vol. 18, no. 1, pp. 75-84, 2010.

[11] G. de Jong, A. Daly, M. Pieters, C. Vellay, M. Bradley, and F. Hofman, "A model for time of day and mode choice using error components logit," Transportation Research Part E, vol. 39, no. 3, pp. 245-268, 2003.

[12] S. Hess, M. Fowler, T. Adler, and A. Bahreinian, "A joint model for vehicle type and fuel type choice: evidence from a crossnested logit study," Transportation, vol. 39, no. 3, pp. 593-625, 2012.

[13] A. Papola, "Some developments on the cross-nested logit model," Transportation Research Part B, vol. 38, no. 9, pp. 833851, 2004.

[14] M. Bierlaire, "A theoretical analysis of the cross-nested logit model," Annals of Operations Research, vol. 144, no. 1, pp. 287300, 2006.

[15] S. Hess and J. W. Polak, "Exploring the potential for crossnesting structures in airport-choice analysis: a case-study of the Greater London area," Transportation Research Part E, vol. 42, no. 2, pp. 63-81, 2006.

[16] M. D. Abkowitz, "An analysis of the commuter departure time decision," Transportation, vol. 10, no. 3, pp. 283-297, 1981. 
[17] K. A. Small, "The scheduling of consumer activities: work trips," American Economic Review, vol. 72, no. 3, pp. 467-479, 1982.

[18] D. McFadden, "Modeling the choice of residential location," in Spatial Interaction Theory and Residential Location, A. Karlqvist, Ed., pp. 75-96, North-Holland, Amsterdam, The Netherlands, 1978.

[19] C.-H. Wen and F. S. Koppelman, “The generalized nested logit model," Transportation Research Part B, vol. 35, no. 7, pp. 627641, 2001.

[20] A. Daly and M. Bierlaire, "A general and operational representation of generalised extreme value models," Transportation Research Part B, vol. 40, no. 4, pp. 285-305, 2006.

[21] S. Bekhor and J. N. Prashker, "GEV-based destination choice models that account for unobserved similarities among alternatives," Transportation Research Part B, vol. 42, no. 3, pp. 243-262, 2008.

[22] R. Cervero, "Built environments and mode choice: toward a normative framework," Transportation Research Part D, vol. 7, no. 4, pp. 265-284, 2002.

[23] R. Ewing and R. Cervero, "Travel and the built environment," Journal of the American Planning Association, vol. 76, no. 3, pp. 265-294, 2010.

[24] M. Bierlaire, "The network of GEV model," in Proceeding of the 2nd Swiss Transport Research Conference, Verita, Switzerland, 2002.

[25] M. Bierlaire, "BIOGEME: a free package for the estimation of discrete choice models," in Proceeding of the 3rd Swiss Transport Research Conference, Monte Verita, Switzerland, 2003.

[26] S. Hess, J. M. Rose, and D. A. Hensher, "Asymmetric preference formation in willingness to pay estimates in discrete choice models," Transportation Research Part E, vol. 44, no. 5, pp. 847863, 2008.

[27] E. Pels, N. Njegovan, and C. Behrens, "Low-cost airlines and airport competition," Transportation Research Part E, vol. 45, no. 2, pp. 335-344, 2009. 


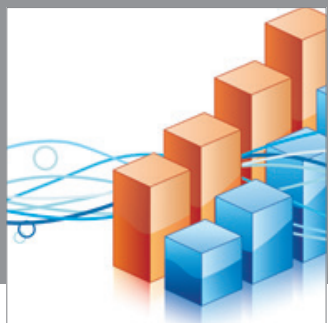

Advances in

Operations Research

mansans

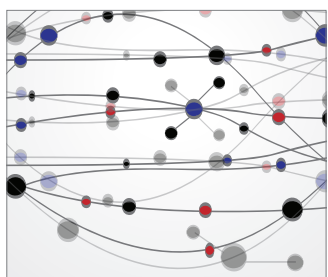

The Scientific World Journal
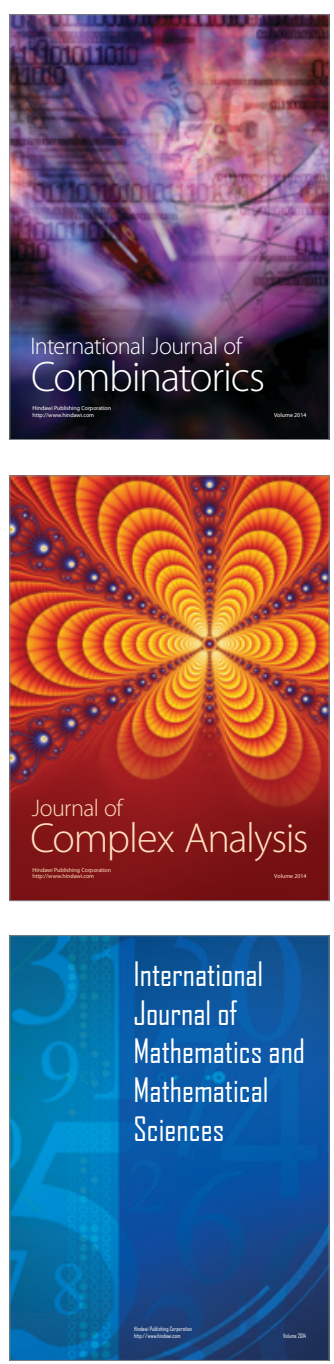
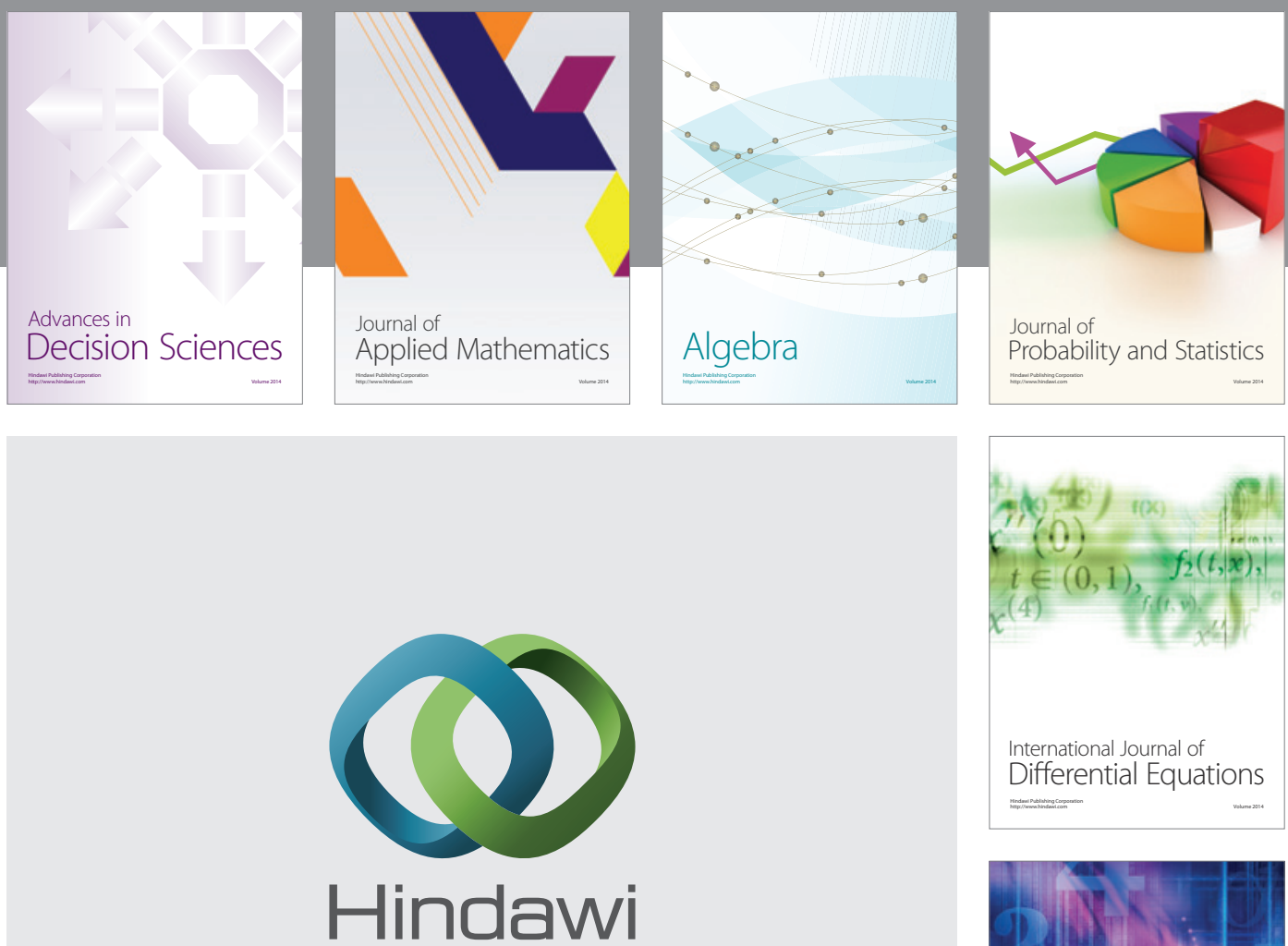

Submit your manuscripts at http://www.hindawi.com
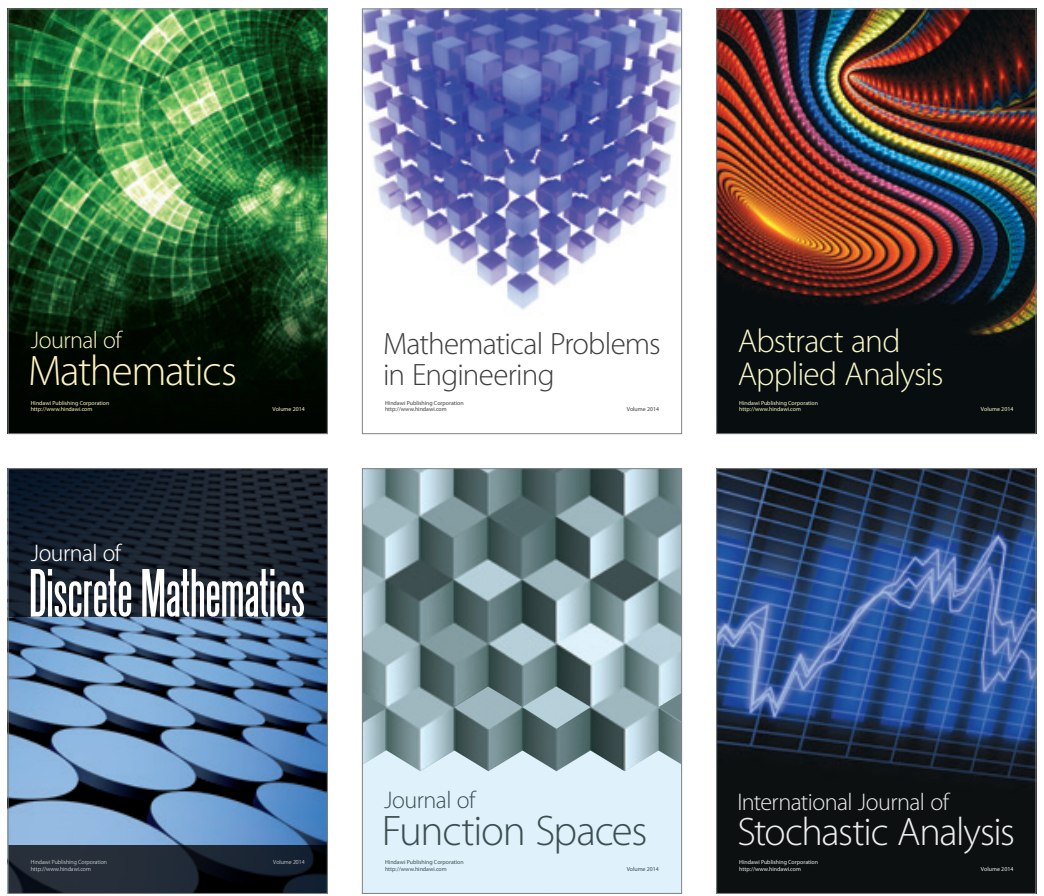

Journal of

Function Spaces

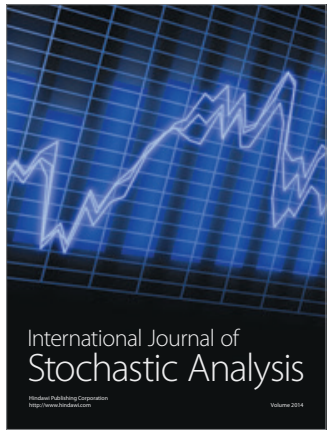

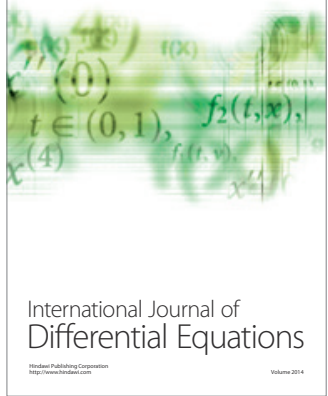
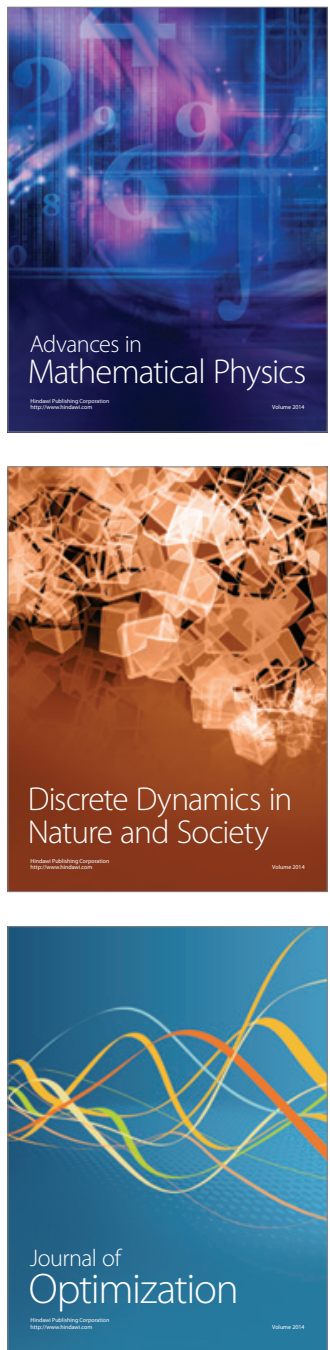